\title{
Fuat Sezgin'in Bilim ve Bilim Tarihi Anlayışı
}

\section{Fuat Sezgin's Understanding of Science and History of Science}

\author{
Doktora Öğrencisi Tuğşat GÜZELOĞLU (iD)1
}

\begin{abstract}
Öz
Bu çalışmada dünyanın en önemli bilim tarihçilerinden birisi olan Fuat Sezgin'in bilim tarihi anlayışına değinilecek ve bilim tarihindeki önemi ortaya konacaktır. Bunun için öncelikle Fuat Sezgin'e göre bilim tarihi nedir sorusunun cevaplanması gerekmektedir. Bilim tarihi, insanoğlunun bilimsel faaliyetlerinin keşfinin tarihidir. Bu nedenle insanlık tarihinin anlaşılmasının yolu bilim tarihinden geçmektedir. Mensubu olduğu kültür ve medeniyet dünyasının izlerini süren Fuat Sezgin, bilim tarihi alanında mazimizi ortaya çıkaran büyük bir düşünürdür. İslam bilimlerinin gerçeğini ve gerçekliğini ortaya koymak adına bilim tarihinde uzun bir yolculuğun sahibidir. Fakat Sezgin'in bilim tarihi çalışmaları ile yaptığı şey bir olaylar sıralaması yapmaktan ziyade bir bilinç oluşturmaktır. İslam medeniyetinin daha iyi anlaşılması ve anlatılması hususunda saysız çalışmalara imza atan Sezgin, bu doğrultuda geçmiş ile gelecek arasında bir köprü kurmayı başarabilmiştir. Bunu yaparken objektif olarak bir gerçeklik resmi sunmuştur. Bu bağlamda bilim ve bilim tarihine olan katkıları göz önüne alındığında Sezgin'in tarihte yeni bir çığır açtığı görülmektedir. Böylece bilim tarihine yeni bir boyut getiren Fuat Sezgin, İslam bilim tarihinin insanlık tarihindeki yerini de ortaya koymuştur. Sonuç olarak, Fuat Sezgin, hakkında söylenenlerden daha fazlasını hak eden bir bilim adamıdır.
\end{abstract}

Anahtar Kelimeler: Bilim, bilim tarihi, bilim tarihçisi, Fuat Sezgin, İslam medeniyeti

Makale Türü: Derleme

\begin{abstract}
In this study, the understanding of the history of science of Fuat Sezgin which is one of the most important science historians in the world, will be discussed and its importance in the history of science will be revealed. For this, first of all, "according to Fuat Sezgin, the question of what is the history of science?" should be answered. The history of science is the history of the discovery of human scientific activities. Thus, the way to understand the history of humanity is through the history of science. Fuat Sezgin, who traces the world of culture and civilization to which he belongs, is a great thinker who reveals our past in the field of history of science. He has a long journey in the history of science on behalf of revealing the truth and reality of Islamic sciences. However what Sezgin does with the study of the history of science is to create a consciousness rather than a sequence of events. Sezgin who undertook countless works in order to understand well and explain the Islamic civilization succeeded in establishing a bridge between the past and the future. He objectively presented a picture of reality by doing this. In this context, considering Sezgin's contributions to the history of science and science, it is seen that Sezgin has opened a new era in history. Therefore, Fuat Sezgin who brought a new dimension to the history of science and revealed the place of the history of Islamic science in human history. As a result, Fuat Sezgin is a scientist who deserves more than what is said about him.
\end{abstract}

Keywords: Science, history of science, science historian, Fuat Sezgin, Islamic civilization

Paper Type: Review

\footnotetext{
${ }^{1}$ Uludağ Üniversitesi, Felsefe ve Din Bilimleri Anabilimdalı, tugsat-sivas@ hotmail.com

Atıf için (to cite): Güzeloğlu, T. (2019). Fuat Sezgin'in Bilim ve Bilim Tarihi Anlayışı. Afyon Kocatepe Üniversitesi Sosyal Bilimler Dergisi, 21(Prof. Dr. Fuat Sezgin Özel Sayıs1), 94-100.
} 


\section{Fuat Sezgin'in Bilim ve Bilim Tarihi Anlayışı}

"Benim mensubu olduğum bir kültür ve medeniyet dünyası var. Bizler, köksüz değiliz. Derinlere kök salan bir medeniyete beşiklik etmişiz. Fakat yüzyıllardır bu medeniyetin görmezden gelindiğini, hakkının yenildiğini ve yaptıklarının elinden alındığını gördüm. İslam medeniyetinin dünya bilimine yaptığı büyük katkıları, bunun farkında olmayan dünyaya tanıtmayı amaç edindim. Bu gayretimin bir kısmı sadece bilim dünyasına hizmet diğer önemli bir gayesi ise İslam dünyasının yitirmiş olduğu kendine saygıyı, güveni ve insanlık tarihindeki yerini hatırlatarak kaybettiklerini iade etmektir.” (Korkmaz, 2009:11)

Bilim tarihi nedir sorusuna birden fazla tanımla cevap vermek mümkün olmakla beraber, bu bilim tarihi tanımları aynı zamanda bilim tarihinin amacını da ortaya koymaktadır. En genel anlamda "Bilim tarihi, nitelikleri 13. yüzyılda şekillenmeye başlayan, özellikle 19. yüzy1l ortalarından itibaren bilim adıyla tanımladığımız sosyal ve kültürel bir olgunun tarihidir." (Gavroğlu,2006:27) Daha açıklayıcı bir tanıma göre ise "Bilim tarihi, doğanın yapısı ve işleyişini anlamaya çalışan insanların tarihi” (Gavroğlu, 2006:14); "uygar dünyayı oluşturan farklı ulusların ve uygarlıkların bilimsel etkinliklerini incelemeye ve karanlıkta kalmış noktaları aydınlatmaya çalışan tarihsel araştırma" (Iliffe, 2016: 19); "insanın evreni araştırması, zaman ve mekân içinde var olan ilişkileri keşfetmesi, elde edilen gerçekleri savunması, yanlışlara ve batıl inançlara karşı savaşması"(Sarton, , 1995: 20-21); "olguları düzenli olarak bir araya getirmek ve olayları doğru bir şekilde sıralamakla birlikte geçmişi yeniden yorumlamayı, dünyayı yeniden inşa etmeyi içeren faaliyet" (Fara, 2012: 13); "uygarlıkların ve ulusların tarihin her dönemindeki gelişimini anlatmak üzerine doğmuş bir bilim dalı”(Ekici, 2013:391) olarak tanımlanmaktadır. Tüm bu tanımlar çerçevesinde "Bilim tarihi uluslar ve uygarlıklar için önemli bir bilim dalıdır. Zira bir ulusun veya uygarlığın tarihsel süreç içerisinde kendi tarihinin faaliyetlerini ortaya koymasının, dünya tarihinde hak ettiği yeri almasının ve insanlık tarihine ismini yazdırmasının yegâne yolu bilim tarihidir.'(Topdemir ve Unat,2008:8-9) Bu bakımdan insanlığın bilimsel faaliyetlerinin ortaya konulmasının en temel yolu bilim tarihi incelemesinden geçmektedir.

Bilim tarihi insanlık tarihinin anlaşılmasındaki en önemli etkinliklerden biridir. Bu açıdan bilim tarihi, çağlar boyunca farklı toplumlar tarafından üretilen bilgi ve bilimin gelişim sürecinin objektif bir çerçeve içerisinde incelenmesi, açılanması, yorumlanması faaliyetidir. Burada objektif olarak bir inceleme son derece önemlidir. Bunun için gerekli olan şey ise her dönemin kendi koşulları içerisinde incelenmesi ve değerlendirilmesidir. Bu inceleme ve değerlendirme durumu bilim tarihinin temel konusunu teşkil etmektedir. O hâlde bilim tarihinin belli başlı soruları ve konularından da bahsetmek mümkündür. Bu manada "İnsanlık tarihinin gelişim aşamalarını sistematik bir biçimde açıklama ve yorumlama faaliyeti olan bilim tarihinin konusu ise doğanın farklı toplumlar tarafından işlenme, modellenme ve anlaşılma tarihini ortaya koymaktır." (Ilıffe,2016:27) Bununla birlikte çok geniş bir alanı kapsayan bilim tarihinin konularını yalnızca bilgi ve bilimle sınırlamak doğru olmayacaktır. "Başka bir ifadeyle bilim tarihinin konusu, bilginin geçmiş olduğu aşamaları belirlemek; bilimsel kuramların doğuşunu ve gelişimini olgusal ve deneysel verilerle betimlemek; bilimin değerini ve önemini sorgulayarak bilimsel etkinliği bütün yönleriyle tanımaya çalışmak; bilimsel etkinliklerin insan yaşamında ne gibi değişikliklere neden olduğunu incelemek; bir toplumun bilime ne zaman katk1 yaptı̆̆ını ortaya koymak; toplumun bilime katkı yapacak düzeye gelmesi için neler yapılması gerektiğini göstermek; bu katkılar esnasında bilim insanlarının kullandıkları yöntemleri, araç ve gereçleri objektif bir perspektiften değerlendirmektir." (Topdemir ve Unat, 2008:7) Bu bağlamda bilim tarihinin konusu geniş bir alanı ilgilendirmekte ve kapsamaktadır. Bununla birlikte bilimin, incelendiği bir alan olarak bilim tarihi disiplini, bilimi tek boyutlu bir olgu olarak değil, sosyal ve kültürel bir olgu olarak ele almaktadır.

Görüldüğg̈ gibi bilim tarihini amacı, bilimsel faaliyetlerin bir kaydını tutmak değildir(her ne kadar ilk eserler böyle ele alınsa da). Fuat Sezgin'de de göreceğimiz gibi, bilim tarihinin asıl amacı, bilimsel düşünmenin insan ile olan ilişkisi bağlamında bir bilinç oluşturmaktır. $\mathrm{Bu}$ 
anlamda "Bilim tarihi faaliyetlerinde bir bilim tarihçisinin görevi ise bilimsel keşifleri sadece art arda sırlamak değil, bilimsel keşiflerin gelişim süreçlerini anlamaya çalışmaktır." (Sarton,1995:17) Daha farklı bir ifade ile bilim tarihçisinin görevi, medeniyetler içinde bilimin doğuş ve gelişimini incelemesi ve bunları yeniden geleceğe taşımasıdır. "Bu bakımdan bilim tarihçisini asıl görevi, bilim insanlarının bilimsel keşiflerini sistematik olarak düzenlemekten ziyade bilimsel bilinçleri canlandırmaktır. İnsan bilincinin gelişimini açıklamak ve bilimsel tutumunu eleştirel yoruma tabi tutmaktır." (Bozkurt,2004:14) Bunu yaparken bilim tarihçisine büyük görev ve sorumlulukların düşmesi de doğaldır. Nitekim objektif bir değerlendirme çağın koşullarına göre her zaman mümkün olmasa da bilim tarihçi bu durumdan taviz vermemelidir. "Bu demek oluyor ki bilim tarihçisinin ödevi, bütünü meydana getiren parçaları gerçeğe uygun bir şekilde duygulardan, önyargılardan uzak bir biçimde tanımak ve tanıtmaktır." (Sezgin,2012:12) Bu bağlamda burada bizi ilgilendiren konu bilim tarihçisi Fuat Sezgin'in bilim tarihini nasıl tanımladığ 1 ve bilim tarihi anlayışını nasıl temellendirdiğidir.

Bilimin açık ve gizli tarihinden bahsetmek mümkündür. Bilimsel buluşların kim tarafından ve hangi zamanda yapıldığı bilimin açık tarihi ile ilgilidir. Bilimin kapalı tarihi ise bilimsel buluşların gerekçeleri ile birlikte ele alınıp bir açığa çıkarma etkinliği olarak karşımıza çıkmaktadır. Bilim tarihi her şeyden önce bize bilimsel düşünceye ve teknolojik gelişmelere katkı sağlayan birçok millet ve medeniyetin varlığını göstermektedir. Dolayısıyla günümüz bilim dünyasının ulaştığı seviyeyi anlamak, ilk olarak bilim tarihinin geçmişini incelemeyi gerektirir. Nitekim bu inceleme aynı zamanda insanlık tarihinin de incelenmesi anlamına gelmektedir. "İnsanlığın ortak bilimsel mirası, süreğen adımlarla, her zaman düz bir çizgi hâlinde olmada da, değişken bir hızla büyümektedir. Tarihte belirli bir zaman dilimindeki bir kültür çevresi, bilimsel mirası küçük olsun büyük olsun bir adım daha ileri taşımak için öncülüğü üstlenmiş daha doğrusu içinde bulunulan koşullar doğrultusunda öncülüğe getirilmişse, tarihi koşullar ve o öncü tarafından ulaşılan seviye, ardılın kaydedeceği olası ilerlemeleri ve bu ilerlemelerin hızını etkileyen faktörleri belirler."(Sezgin, 2010:10) Bu noktada Fuat Sezgin, bilimin geçmişini izleyerek, bilimin kapalı tarihini aydınlatmayı kendine hedef edinmiştir.

Dünyanın önde gelen bilim tarihçilerinden birisi olan Fuat Sezgin, İslam bilim tarihi üzerine yapmış olduğu çalışmaları ile tanınmış bir bilim insanıdır. Fuat Sezgin, İslam bilim tarihi alanındaki çalışmaları ile kendi bilim ve kültür dünyasına önemli katkıları ortaya çıkardığı gibi Batı bilim ve kültür dünyasındaki önyargıları da kırmak için çaba göstermiştir. Bu çabaları gerçekleştirmek amacıyla Fuat Sezgin'in yaptığı şey, İslam bilim ve medeniyetinin çalışmalarını objektif bir değerlendirme ile ele almaktır. Dolayasıyla $\mathrm{O}$, bu süreçte Batının öznelliğe dayanan bilim tarihi anlayışını kabul etmemiş ve eksikliklerini ortaya koymak için çalışmıştır. Bu bağlamda Sezgin, bilim tarihi yolculuğuna, 800 yıl boyunca Arap İslam kültür çevresinde geliştirilmiş bilimsel başarıların varlığını ortaya koymak için çıkmıştır. Dolayısıyla $\mathrm{O}$ bilim tarihindeki esas amacını şu şekilde ifade etmektedir: “... Tek amacım, İslam topluluğuna bağlı insanlara, özellikle Türklere, ister dindar ister dinsiz olsunlar, İslam bilimlerinin gerçeğini tanıtmak, onları benlik duygularını hırpalayan yanlış yargılardan kurtarmak ve onlara ferdin yaratıcılığına karşı olan inancı kazandırmaktır.” (Sezgin, 2012:12)

Fuat Sezgin' e göre bilim tarihi, sadece bir geçmişin tasvirini ortaya koymak değil, yeni bilimsel ilerlemelerin de gelişmesine katkı sağlamaktır. "Bilim tarihi, bilginin tarih içerisinde geçirdiği farklı süreçleri, bilim olarak adlandırdığımız bilgi çeşidinin nasıl oluştuğunu, farklı milletlerin bilime katkılarını, bilim adamlarının ne tür bir etkinlik gerçekleştirdiklerini, yöntem ve metotlar ile bilimsel başarıların, uygulamaların, insan ve toplum üzerine olan etkilerini inceler. Bilim tarihi aynı zamanda bilimsel başarıların, toplumların bilime katkı yapacak düzeye kavuşmaları için nelerin yapılması gerektiği gibi konuları da tarihi gelişimi içerisinde somut örneklere dayanarak ortaya koyar."(Yakıt ve Durak, 2002:14) Bu bağlamda İslam bilim tarihçisi Sezgin'in bilim tarihinin ne olduğuna ilişkin düşünceleri onun çalışmalarını anlayabilmek için büyük öneme sahiptir. O hâlde Sezgin'in yaptığı bilim tarihinin tanımını ele almak gerekir. Fuat Sezgin, 'Bilim tarihi nedir?' sorusunu şu şekilde cevaplamaktadır : "Bilim tarihi ne demek? Bilim 
tarihini çok çeşitli şekillerde tarif edebilirsiniz. Ama bugün aklıma geleni size söyleyeceğim. Beşeriyetin başlangıçtan bugüne hayat şartlarını geliştirmek, yaşadığı kâinatı tanımak hususundaki bütün çalışmalarının neticesini gösterme gayretidir.”(Korkmaz, 2009:185) Böylece Fuat Sezgin'e göre bilim tarihinde, en büyük görev, bilimlerin kendilerinden önce ne yaptığının tespit edilmesidir. Bu nedenle Sezgin'in çalışmaları bibliyografya zemininde bize bir gerçeklik resmi sunmaktadır. Nitekim bir astronom, bir fizikçi, bir matematikçi olmadığı hâlde, Sezgin'in bu bilim alanları ile ilgili verdiği bilgiler bunu doğrular niteliktedir.

Bilim tarihinin tanımını ve bilim tarihçisinin yapması gereken ilk şeyi bu şekilde ifade eden Fuat Sezgin'in bilim tarihindeki amacını da ortaya koymak yerinde olacaktır. Sezgin açısından bilim tarihinin amacı "İslam bilim tarihinin insanlık tarihindeki konumunu ve etkisini objektif olarak açığa çıkarmaktır. İslam medeniyet tarihi hakkında Müslümanlar ve Batılılar arasında yaygın yanlış kanaatleri düzeltmek ve Müslümanların insanlık tarihindeki konumlarını ortaya koymaktır.'(Awrahim,2017:366) Sezgin'i bu amaca yönelten birçok sebep olmakla birlikte en önemli sebeplere baktığımızda birinci sebebin Sezgin'in bilime hizmet etme isteği görülmektedir. İkinci sebep ise Sezgin'in İslam medeniyetinin bilimsel başarılarının Batı dünyasındaki düşünürler tarafından sürekli olumsuz düşünceler çerçevesinde ele alınmasıdır. Dolaysıyla Sezgin, Batı uygarlıkları tarafından görmezden gelinen büyük başarılara karşı İslam biliminde var olan bilimsel başarıların ne kadar özgün olduklarını ortaya koymaya çalışmaktadır. Nitekim Sezgin'e göre "İslam dünyası, geç antik dönem ile Avrupa yakın çağı arasındaki devirde, gelişime en müsait ve etkisi en güçlü kültür sahasıdır ve de eski dünya ile oluşmaya namzet Avrupa arasındaki yegâne gerçek bağdır." (Sezgin, 2010:12)

Hiç şüphesiz Fuat Sezgin'in bilim tarihi anlayışının gelişmesinde ve şekillenmesinde hocalarının etkisi büyüktür. Bu noktada ise isminin zikredilmesi gereken en önemli isim şüphesiz Hellmut Ritter'dir. İstanbul Üniversitesi Şarkiyat Araştırmaları Enstitüsünün İslami Bilimler ve Orientalistik bölümünde görev yapan Ritter'in Sezgin'i bilim tarihi alanına sevk ederek teşvik etmesi önemlidir. Zira Sezgin'in ilk amacı matematik okuyup mühendis olmak iken, hocası Ritter sayesinde İslam bilim tarihi çalışmalarına başlayan Sezgin'in, yine dil öğrenme konusunda da hocasının sözünden çıkmadığı bellidir. Nitekim Sezgin bu sayede yararlandığı kaynakları çeviriden değil, o dilin kendisini öğrenerek okuma noktasına gelmiştir.

Sezgin'in bilim tarihine olan bakışını ve bilim tarihindekini önemini anlatan bir diğer nokta onun eserleridir. Tüm ömrünü adadığ 1 bu eserler bilime ve bilim tarihine yapılan katkıların gerçekliğini apaçık şekilde ortaya koymaktadır. Nitekim bu bağlamda "İslam Uygarlığında Astronomi Coğrafya ve Denizcilik", "Kâtip Çelebi'nin Esas Kitabı-1 Cihannüma'sı ve Coğrafya Tarihindeki Yeri”, "İslam Uygarlığında Mimari, Geometri, Fizik, Kimya, Tıp", "Buhari’nin Kaynakları", "İslam' da Bilim ve Teknik”, “Amerika Kıtası'nın Müslüman Denizciler Tarafından Kolomb Öncesi Keşfi ve Piri Reis" adlı eserleri Sezgin'in bilim tarihi yolculuğunda karşımıza çıkan ve O'nun bilim tarihi anlayışını bize en güzel şekilde sunan önemli eserleridir.

Fuat Sezgin, eser ve görüşleri ile bilim tarihine yeni bir boyut getirdiği gibi günümüz İslam dünyası için ayrı bir önem taşımaktadır. Unutulan bir bilimsel geçmişi yeniden hatırlatan Sezgin, bu sayede insanlarda bilimsel araştırma bilincini de canlı tutmaktadır. Sezgin bunu yaparken İslam medeniyetinin büyük mirasını 17 ciltlik eseri ile ortaya koymaktadır. Bu eser, bibliyografik eser olan Arap-İslam Bilimleri Tarihi (Geschichte des arabischen Schrifttums-GAS) adlı eserdir. Bu eserde Sezgin, temel İslam bilimlerini tanıttıktan sonra, tarihsel süreç içerisinde Müslüman âlimlerin yaptığı bilimsel faaliyetlerini ele almıştır. Aslına bakılırsa bu eserin ortaya çıkmasında Carl Brockelmann oldukça etkili görünmektedir. Çünkü "Fuat Sezgin, Doğu Bilimi ve Türkoloji üzerine çalışmalar yapan bilim adamı Alman Carl Brockelmann'ın (18681956);Arap Edebiyatı Tarihi ve İslam Milletleri ve Devletleri Tarihi gibi çalışmalarındaki eksiklikleri fark etmiş ve bunları tamamlamak maksadıyla, 1954 yılında İslam Bilim Tarihi ile ilgilenmeye başlamıştır." (Balta,2004:489) Bununla birlikte yanlış bir İslam medeniyeti algısını değiştirmek isteyen Sezgin, bu çalışmasıyla İslam medeniyetinin uygarlıklar tarihinde bir dönüm noktası durumunda olduğunu göstermiştir. 
İslam medeniyetinin bilimsel gerçekliklerini eserlerinde bu şekilde ortaya koyan Fuat Sezgin için bilim tarihinde bir diğer önemli nokta, bilimler tarihinin bir bütün olarak ele alınması gerektiğidir. Nitekim "Bilimin geçmişi günümüzden en az dört bin yıl öncesine kadar uzanır. Bu zaman dilimi boyunca dünya üzerindeki her yerleşik millet bilimin ve dolayısıyla uygarlığın gelişmesine az veya çok katkıda bulunmuştur. Çünkü bu entelektüel etkinlik bütün insanlar için ortak olup, din, dil ve milliyet sınırlarını aşar. Tarih boyunca her millet bilime yaptığı katkının büyüklüğüyle orantılı olarak uluslararası olan uygarlığın yaratılmasına katkıda bulunmuş ve ondan pay almıştır.”(Gökdoğan,2008:9)Bilimi sadece tek bir uygarlık ya da ulusun ürünüymüş gibi ele almak yerine birçok uygarlığın ortak ürünü olarak ele almak daha doğru olacaktır. Bu noktada Sezgin görüşlerini desteklemek için kaynak olarak sadece İslam düşünürlerini göstermemekte birçok yabancı düşünürle de bu konuda ortak görüş sergilemektedir. Fransız oryantalist düşünür Joseph T. Reinaud (1795-1865) medeniyetler tarihinin bütünlügüü ile ilgili olarak şunları söylemiştir: "Rastlantı, tekniklerin ve sanatların ilerlemesinde çok büyük bir rol oynamaz. İnsanlık bütün keşiflerinde istikrarlı bir şekilde ileriye doğru ani bir sıçrayışla değil, adım adım hareket eder. Her zaman aynı hızla ilerlemez, fakat hareket süreklidir. İnsan icat etmez, sonuçlar çıkarır. Mesela insan bilgisinin bir alanını ele alalım. Bu alanın tarihi, yani ilerleme tarihi, aralıksız bir zincir oluşturur."(Sezgin,2008:13) "Buradan da anlaşılacağı üzere, medeniyet tarihinin tek bir topluma veya kültüre özgü bir gelişme olduğu doğru değildir." (Sayıl1, 1999:10$11)$.

Fuat Sezgin, İslam bilim tarihindeki gerçeklerin açığa çıkarılmasında önemli katkılar sağladığı gibi bilim tarihine yeni bir perspektif kazandıran bilim insanıdır. "İslam medeniyetinin öteki kültür dünyalarından aldığı bilimleri geliştirdiğini, yeni bilim alanları oluşturduğunu ve özgün bilimsel faaliyetler gerçekleştirdiğini düşünen Sezgin, İslam dünyasında bilimsel faaliyetlerin 9. yüzyılın ilk yarısından başlayıp 16. yüzyılın sonlarına kadar devam ettiğini ileri sürmüş̧ür.'(Sezgin, 2011: 92-94.) Nitekim Fuat Sezgin'e göre bu anlamda İslam medeniyetinin kendine has prensiplerinden bahsedilebilir. Fuat Sezgin bu prensipleri şu şekilde ifade etmektedir: "Bilimler tarihçisi için, büyük safhaların kendine has temel değerlerinin belirtilmesi işi kolay olmuyor. Ben şahsen yıllar boyunca İslam bilimler safhasının kendine has prensipleri olarak şunlara ulaşabildiğimi sanıyorum:

1.Adil tenkit prensibi

2.Vazıh bir tekâmül kanunu düşüncesi

3. Kaynak zikretmede diğer kültür dünyalarında olduğundan daha çok gösterilen gayret

4. Bilim tarih yazarlığının 10. yüzyıldan itibaren ortaya çıkışı ve gelişmesi

5.Tecrübe ile teori arasında bir denge kurma prensibi ve tecrübenin araştırmada sistemli bir şekilde kullanılacak bir vasıta olarak yer alması

6. Uzun süreli gözetleme prensibi; bunun sonucu olarak rasathanelerin icadı

7. Bilimin sadece kitaptan değil, hocadan ve kitaptan öğrenilmesi; buna bağlı olarak ilk üniversitelerin ortaya çıkışı.”(Sezgin, 2009:7-8)

Bu prensiplerle birlikte sadece Türkiye'de değil dünyada İslam bilim medeniyetinde bilimsel çalışmaların varlığını ortaya koyan Sezgin'in Frankfurt-Goethe Üniversitesi'nde birçok araştırma ve öğretim faaliyetleri mevcuttur. Aynı zamanda O, Arap-İslam Bilimler Tarihi Araştırmaları Enstitüsü'nün de kurucusudur. Fuat Sezgin (Sezgin, 2014:4) bu enstitünün amaçlarını da şu şekilde sıralamaktadır:

1. Bilim adamlarının bir kısmı tarafından Arap İslam bilimleri tarihini araştırılması ve Arap İslam bilim adamlarının bilim tarihindeki yerinin anlatan eserlerin neşredilmesi, mesela Arapça orijinal metinlerin yeniden yayınlanması ve Avrupa dillerine tercüme dilmesi ile bilimsel bir derginin yayınlanması. 
2. Arap İslam bilimleri tarihinin öğretilmesi için öğretmen ve araştırmacıların yetiştirilmesi. Bu hedefe kolay ulaşmak için üstün kabiliyetli öğrencilere burs verilecektir. kurulmas1.

3. Bir merkezi kütüphanenin ve Arapça yazmalarından oluşan mikrofilm arşivinin

4. Profesör, araştırmacı ve kütüphanecilerin enstitümüzde araştırma yapmaları, seminer ve ilmi müzakerelere katılmaları için davet edilmeleri.

5. En azından bilim tarihi dalında Batı'daki meslektaşlarımızın elde ettikleri araştırma neticelerinin Arap-İslam ülkelerindeki meslektaş ve öğrencilere zamanında ulaştırılması.”

Benzer şekilde İstanbul'daki İslam Bilim ve Teknoloji Tarihi Müzesi'nin de kurucusu olan Sezgin, böylece bilim tarihindeki İslam medeniyetinin izlerini ortaya çıkarmak için kullandığ 1 sesini daha geniş kesimlere duyurmak niyetindedir. Dolayısıyla bu müze ile birlikte bu müzedeki aletleri tanıtıcı mahiyette İslam'da Bilim ve Teknik adlı katalog hazırlamıştır. Sezgin, kurduğu müzenin ve yayınladığı kataloğun amacını şöyle ifade etmektedir: "Arap-İslam fen bilimler ve tekniği çerçevesinde kullanılmış, geliştirilmiş ve icat edilmiş araç-gereçleri, avadanları tanıtmak, bize ulaşmış değillerse yeniden imal etmek bu araştırma sonuçlarını etkili şekilde aktarabilmenin bir yoludur. Kurduğumuz müze ve bu müzede sergilenen parçaları tanıtan katalog bu tarz bir aktarımı hedeflemektedir." (Sezgin, 2008:13)

\section{Sonuç}

Bilim, benliğimizde önemli bir yeri olan medeniyetimizin büyük bir mirasıdır. Bilim tarihi ise bilimin tarihinin ele alındığı, insanlığın bilimsel faaliyetlerinin ön plana çıkarıldı $\breve{1}$ bir insanlık tarihinin ortaya konmasıdır. Fuat Sezgin, bilimler tarihinin bütünlügünü ortaya koymak için bilim tarihi yolculuğuna çıkan büyük bir bilim tarihçidir. Sezgin, büyük İslam medeniyetini ve bilimsel başarılarını öğrenmemiz noktasında çı̆̆ır açan büyük bir dâhidir. İslam Arap kültür dünyasının bilimsel mirası görmezden gelindiği gibi peşin hükümlerle değerlendirilmiştir. Oysaki Müslüman bilim adamlarındaki sistemli ve uygulamalı bilimsel faaliyetlerin varlığ onların deney, teori ve pratik arasındaki ilişkiyi göz ardı etmeden bilimsel faaliyetler gerçekleştirdiklerini göstermektedir. Bu yüzden Fuat Sezgin için önemli olan zengin bir bilimsel mirasın ortaya çıkmasını sağlamak ve bu mirasın daha iyi yerlere gelmesi için çalışmaktır. Bu amaçla Sezgin'in yaptığı şey, bilimin tarihini ele alırken tarafsız olmaktır. Nitekim "Bu toplumların doğru bir biçimde analiz edilmeleri tarihsellikten yoksun sübjektif ölçütlerle değil, sosyal-kültürel bir zaman ve mekân perspektifi içinde objektif ölçütlerle değerlenmeyi gerektirmektedir." (Gavroğlu, 2006:30)

Uzun yıllar süren çalışmaları sonucunda Fuat Sezgin, İslam dünyasının insanlığın gelişmesine ve ilerlemesine olan katkıları açıkça ortaya koymuştur. Bu anlamda Fuat Sezgin'in çalışmaları bilim tarihinde bir dönüm noktasıdır. Nitekim Fuat Sezgin'in bu çalışmaları İslam dünyasının bilimsel başarılarının ön plana çıktığını gösteren kaynak niteliği taşımaktadır. Dolayısıyla Fuat Sezgin, geçmişi geleceğe taşıyabilen dünyaca ünlü değerli bir Türk bilim tarihçisidir.

Son olarak; Fuat Sezgin, geride bıraktığı eserler ve kurumlarla büyük bir değere sahiptir. 93 yaşında hayata veda eden bilim adamı Fuat Sezgin ile yalnızca geçmişimiz ortaya çıkmamıştır. Zira onun ortaya koymaya ömrünü adadığı, kimliğimiz de Fuat Sezgin'in sayesinde bizi geleceğe taşıyacaktır. Bunun için yapılması gereken en önemli şey Fuat Sezgin'in eserlerini anlamak ve onun yönlendirdiği yolda yeni bilimsel buluş ve faaliyetlerin gerçekleşmesi için çalışmak olacaktır. 


\section{Kaynakça}

Awrahim, T.(2017). Tarihçi Fuat Sezgin ve İslam Medeniyeti Tarihinde Düzelttĭgi Kavramlar, Mukaddime 8.

Balta, İ. (2004). Batı Uygarlığı, İslam Medeniyetinin Çocuğudur, Aksiyon Dergisi. 489.

Bozkurt, N. (2004). Bilimler Tarihi ve Felsefesi, İstanbul: Morpa Kültür Yayınları.

Ekici, A. (2013). Tarihî Uyanışın Mimarı: Prof. Dr. Fuat Sezgin, Genç Hukukçular Hukuk Okumalarl, (Ed. Muharrem Balcı) İstanbul: Matbaa Basım.

Fara, P. (2012). Bilim: Dört Bin Yıllık Tarih, (Çev: Aysun Babacan),İstanbul: Metis Yayıncılık.

Gavroğlu, K. (2006). Bilimlerin Geçmişinden Tarih Üretmek, (Çev: Ari Çokana), İstanbul: İletişim Yayınları.

Gökdoğan, M. D. (2008). Türklerin Bilime Katkılarl, Ankara: Atatürk Kültür Merkezi Yayınları.

Iliffe, R. (2016). Bir Disiplinin Gelişim Hikâyesi: Bilim Tarihi, (Çev: Sedef Beşkardeşler ve Tarık Tuna Gözütok),İstanbul: Lotus Yayınevi.

Korkmaz, T. (2009). 20. Yüzyll İslam Bilim Tarihi Çalışmaları: George Sarton ve Fuat Sezgin Örneği, Marmara Üniversitesi, Sosyal Bilimler Enstitüsü, Yayınlanmamış Yüksek Lisans Tezi, İstanbul.

Sarton, G. (1995). Antik Bilim ve Modern Uygarlık, (Çev: Melek Dosay ve Remzi Demir),Ankara: Gündoğan Yayınları.

Sayıl1, A. (1999). Bilim Tarihi, Ankara: Gündoğan Yayınları.

Sezgin, F. (2008). İslam'da Bilim ve Teknik Cilt I, (Çev: Abdurrahman Aliy) İstanbul: İstanbul Büyükşehir Belediyesi Kültür A.Ş. Yayınları.

Sezgin, F. (2012). İslam Kültür Dünyasının Bilimler Tarihindeki Yeri, İçinde: İslam Bilimler Tarihi Üzerine Konferanslar,(Ed. Zeynep Berktaş ve Tuğçe İnceoğlu),İstanbul: Timaş Yayınlar1.

Sezgin, F. (2012). Tanınmayan Büyük Çağ: İslam Bilim ve Teknoloji Tarihi, (Ed.Resul Turan),İstanbul: Timaş Yayınları.

Sezgin, F. (2014). 1984 Yllından 2011 Yllına Kadar Arap-İslam Bilimleri Tarihi Enstitüsü Yayınlarına Yazllan Avrupa Dillerindeki Önsözler, İstanbul: Timaş Yayınları.

Sezgin, F. (2009). İslam Uygarlığında Astronomi Coğrafya ve Denizcilik (Çev:Abdurrahman Aliy),İstanbul: Boyut Yayınları.

Sezgin,F. (2011). İslam'ın Bilimler Tarihindeki Yaratıcı Yerine Bir Bakış, Adam Akademi, (1), 89-98.

Topdemir, H. G. ve Unat, Y. (2008). Bilim Tarihi, Ankara: Pegem Akademi Yayınevi.

Yakıt, İ. ve Durak, N. (2002). İslam'da Bilim Tarihi, Isparta: Tuğra Matbaası. 